\title{
The effect of skin temperature on vibrotactile sensitivity
}

\author{
BARRY G. GREEN \\ John B. Pierce Foundation Laboratory, New Haven, Connecticut 06519 \\ and \\ Yale University, New Haven, Connecticut 06520
}

\begin{abstract}
The effect of skin temperature on detection of vibrotactile stimuli was measured for vibrations of 30 and $250 \mathrm{~Hz}$. Data for the $250-\mathrm{Hz}$ stimulus supported the results of Weitz (1941), who found that thresholds for 100-, 256-, and $900-\mathrm{Hz}$ vibration varied as a $U$-shape function of skin temperature with a minimum at about $37^{\circ} \mathrm{C}$. Temperature had a negligible effect on sensitivity at $30 \mathrm{~Hz}$. A second experiment examined a range of frequencies between 30 and $250 \mathrm{~Hz}$. Cooling greatly lowered sensitivity only to $150-$ and $250-\mathrm{Hz}$ stimuli. Warming reduced sensitivity less, but more uniformly across frequencies. It was concluded that cooling may affect vibrotactile thresholds by decreasing the sensitivity of Pacinian corpuscles; the reason for the decrease in sensitivity due to warming is unclear.
\end{abstract}

Severe cold numbs the sense of touch. Despite the commonplace nature of this experience, relatively little has been done to quantify it. Early studies by Allers and Halpern (1922) and Moore (1910) seemed to reveal that the threshold for punctiform touch varies as a $\mathrm{U}$-shaped function of skin temperature, with a minimum at about $37^{\circ} \mathrm{C}$. But in both studies stimulus control and measurement left much to be desired. Later, Weitz (1941) seemed to corroborate the earlier findings. He noted that on hairy skin pressure-sensitive and vibration-sensitive "spots" coincided, and found that thresholds for punctiform vibration also varied as a $U$-shaped function of skin temperature, with a minimum at $37^{\circ} \mathrm{C}$. Weitz concluded that temperature affected detection by altering biochemical processes in mechanoreceptors sensitive to both pressure and vibrotactile stimulation.

But recent findings in electrophysiology and vibrotactile psychophysics have challenged the view that punctiform pressure and vibration are always mediated by the same receptors. Pressure receptors tend to be slowly adapting and amplitude-sensitive, vibration receptors quickly adapting and velocitysensitive (Harrington \& Merzenich, 1970; Merzenich \& Harrington, 1969). Since these different response properties undoubtedly derive from different biophysical processes, it seems questionable that temperature would affect the different receptors in identical ways.

One can find out indirectly by psychophysical experiment. At least two receptor populations seem

Reprint requests may be sent to: Barry G. Green, John B. Pierce Foundation Laboratory, 290 Congress Avenue, New Haven, CT 06519. to mediate the perception of vibrotactile stimuli: One, composed of so-called low-frequency receptors, reacts most readily to vibrations below about $80 \mathrm{~Hz}$; the other, a high-frequency system, reacts to vibrations above $80 \mathrm{~Hz}$. The high-frequency system is believed to be composed of Pacinian corpuscles (Merzenich \& Harrington, 1969; Mountcastle, Talbot, Darian-Smith, \& Kornhuber, 1967; Talbot, Darian-Smith, Kornhuber, \& Mountcastle, 1968; Verrillo, 1963, 1968), whereas no specific receptor has been identified for the low-frequency system. The obvious question is: Since different receptors may be involved, does skin temperature affect lowand high-frequency vibration in the same way?

The answer to this question was sought in two experiments. The first managed to replicate Weitz's result with a $250-\mathrm{Hz}$ stimulus, but revealed no effect of skin temperature on detection of a $30-\mathrm{Hz}$ stimulus. The second investigated how skin temperature influenced thresholds over a range of frequencies between 30 and $250 \mathrm{~Hz}$.

\section{EXPERIMENT 1}

\section{Method}

Subjects. Two women (C.K. and C.T.) served as subjects in the main experiment. One male (D.S.) was tested in a preliminary experiment that is included below. The subjects had extensive experience in psychophysical tasks, but none had participated previously in vibrotactile experiments. All were given practice before data collection began.

Apparatus. Sinusoidal signals were generated by a General Radio 1210-C oscillator. The duration and timing of the signals was controlled at the output of the oscillator by a GrasonStadler 829C electronic switch. From the electronic switch, the signal passed through an impedance matching transformer before going to a Grason-Stadler E3262A recording attenuator. The output from the attenuator was amplified (General Radio 
Type 1206-B) and passed through a second impedance matching transformer before going to the the vibrator, a Brüel and Kjaer 4810 minishaker.

Skin temperature was controlled by immersing the subject's forearm and hand in a water bath that measured $45 \mathrm{~cm}$ long, $12.5 \mathrm{~cm}$ wide, and $11 \mathrm{~cm}$ deep. Two thermocouples monitored water and skin temperatures: One thermocouple was suspended from the side of the bath $4 \mathrm{~cm}$ from the bottom; the second was attached to the subject's skin by tape (leaving the thermocouple tip exposed) approximately $2 \mathrm{~cm}$ proximal to the site of mechanical stimulation. Water and skin temperatures were monitored continuously.

The vibrator was mounted on a drill stand that provided control over the penetration of the contactor into the skin. Since the vibrator contacted the exposed surface of the hand, the point of contact was easily determined visually. After contact was made, the contactor tip was impressed $1 \mathrm{~mm}$ into the skin by removing a shim from the lever assembly of the drill stand.

The contactor was a steel pin with a flat surface $.008 \mathrm{~cm}^{2}$ in area. The small contactor was used both to approximate the size used by Wietz $\left(.0006 \mathrm{~cm}^{2}\right)$ and to avoid production of thermal gradients under the contactor. No rigid surround was used. Vibration amplitudes were measured using an accelerometer (Bolt, Beranek, \& Newman Model 501A) in conjunction with optical calibrations.

Procedure. Each session was begun by filling the bath with water at a temperature either a few degrees below $20^{\circ} \mathrm{C}$ (to begin an ascending remperature series) or a few degrees above $42^{\circ} \mathrm{C}$ (to begin a descending series). Due to the thermal radiation and absorption of the hand and arm, it was necessary to use initial water temperatures a few degrees cooler or warmer than the target temperature in order to obtain a skin temperature significantly above or below normal skin temperature. (For example, to reach a stable skin temperature of $20^{\circ} \mathrm{C}$ sometimes required an initial water temperature of $16^{\circ}-18^{\circ} \mathrm{C}$.) With the water bath filled, the subject's left forearm and hand (thermocouple attached) were placed in the bath. The arm was positioned so that the side of the hand and little finger rested on the floor of the bath (i.e., thumb and index finger up), with the fist loosely clenched. The region stimulated was a spot on the fleshy, hairless skin midway between the base of the thumb and index finger. The spot was marked with ink to provide accurate re-location on subsequent days. The test site was chosen for its easy accessibility, relatively high sensitivity, and for the comfort it afforded the subject.

After water immersion, skin temperature was adjusted by stirring and adding additional cool or warm water as necessary. When skin temperature stabilized (requiring roughly $2-3 \mathrm{~min}$ ), the contactor was lowered $1 \mathrm{~mm}$ into the skin. Threshold was then measured using the Békésy (1960) tracking procedure. The subject "tracked" the stimulus until the experimenter judged that the oscillations had stabilized. A stable level was usually reached within 1-3 min, after which the subject lifted her or his arm from the bath and quickly dried it. Every effort was made to minimize the duration of immersion to avoid possible changes in the physical properties of the skin. Immersions lasted from 3 to $6 \mathrm{~min}$, with rest periods of approximately $5 \mathrm{~min}$ between trials.

Skin temperatures studied included $20^{\circ}, 24^{\circ}, 34^{\circ}, 37^{\circ}, 40^{\circ}$, and $42^{\circ} \mathrm{C}$. Thresholds at these temperatures were measured for $30-$ and $250-\mathrm{Hz}$ stimuli on alternating days, and the order of temperatures tested (ascending or descending) was likewise alternated. Five observations were obtained per subject for both frequencies at each temperature. The vibratory stimuli lasted $500 \mathrm{msec}$, had 10-msec rise-decay times, and were presented every 1,500 msec.

Two subjects (C.K. and D.S.) were tested in the apparatus with the water bath empty to assess the possible effect of hydrostatic pressure on sensitivity. Normal ("dry") skin temperatures during the tests were $30^{\circ}-31^{\circ} \mathrm{C}$. The "dry" data were compared to "wet" data collected with the hand submerged at a skin temperature of $37^{\circ} \mathrm{C}$, the temperature at which the skin should be most sensitive to vibration (Weitz, 1941). The data are plotted in Figure 1. There is a slight tendency toward poorer sensitivity when the arm and hand are immersed in water, even though threshold should be lower at $37^{\circ}$ than at $31^{\circ} \mathrm{C}$. But with the exception of the points at $80 \mathrm{~Hz}$, the effect of immersion is not large.

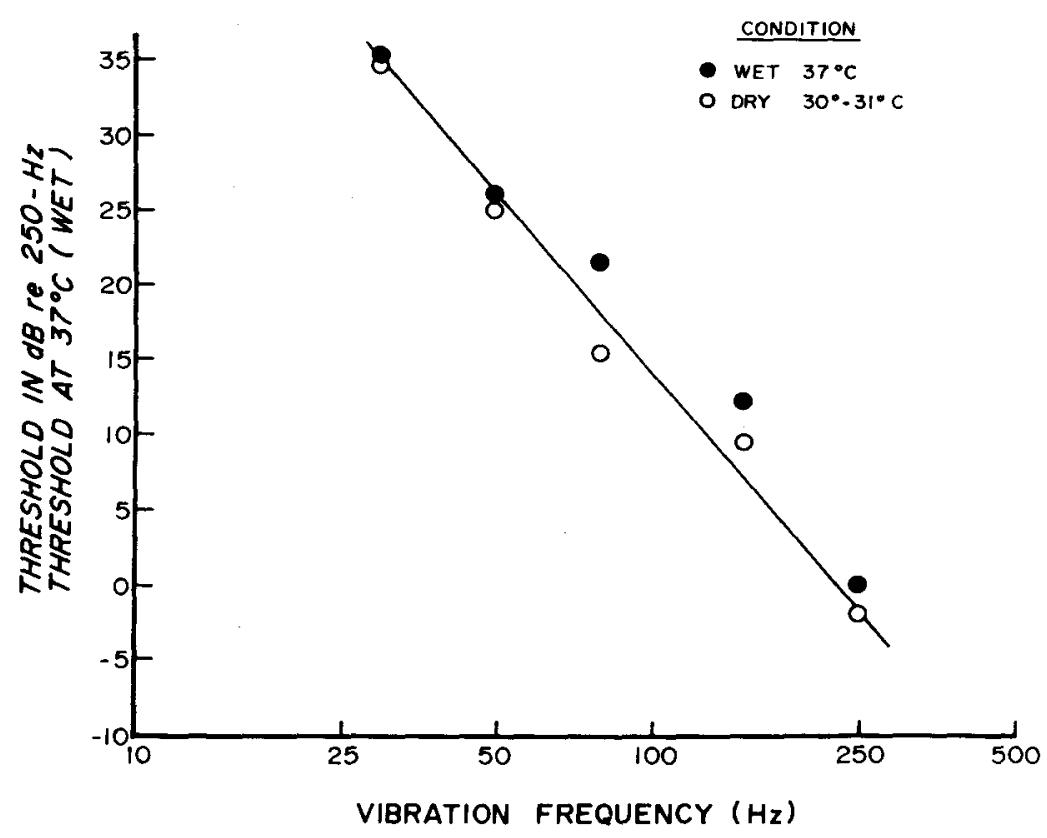

Figure 1. Thresholds measured with the water bath empty $(O-$ "dry" condition, skin temperature $30^{\circ}-31^{\circ} \mathrm{C}$ ) and filled ( $\bullet$ "wet" condition, skin temperature $37^{\circ} \mathrm{C}$ ). The data are mean decibel values referenced to the $37^{\circ} \mathrm{C}$ "wet" thresholds at $250 \mathrm{~Hz}$ for each subject (reference values were $.4 \mu$ for D.S., $1.9 \mu$ for C.T.). A line having a slope of $-12 \mathrm{~dB}$ per doubling of frequency has been fitted to the data with the restriction that it pass through the data points at $30 \mathrm{~Hz}$. 
A line having a slope of -- $12 \mathrm{~dB}$ per doubling of frequency drawn through the data shows that threshold varies with frequency close to the way predicted by Verrillo for high frequencies (Verrillo, 1968). It is interesting, however, that the functions do not have the characteristic flat slope over the range of low frequencies that Verrillo has reported.'

\section{Results}

Figure 2 shows the individual data for two subjects for the $250-$ and $30-\mathrm{Hz}$ stimuli. Points are the medians of five observations. The results for $250 \mathrm{~Hz}$ confirm the findings of Weitz (1941). The U-shaped functions have their minima at $34^{\circ}$ and $37^{\circ} \mathrm{C}$, and cooling had a larger effect than did warming over the range of temperatures tested. As the skin is cooled from $34^{\circ} \mathrm{C}$ to $20^{\circ} \mathrm{C}$, threshold increases at a rate of slightly more than $1 \mathrm{~dB} /{ }^{\circ} \mathrm{C}$ for both subjects. The rate of change in threshold with warming is similar, but the data indicate that sensitivity may not continue to decrease at the same rate above $42^{\circ} \mathrm{C}$. Neither higher nor lower temperatures could be tested without causing pain.

The effect of cooling is strikingly absent for the $30-\mathrm{Hz}$ stimulus. Both subjects, however, showed a tendency toward somewhat higher thresholds as temperature rose. The pooled data (two subjects) for both frequencies are shown in Figure 3. The difference between the $30-$ and $250-\mathrm{Hz}$ functions is

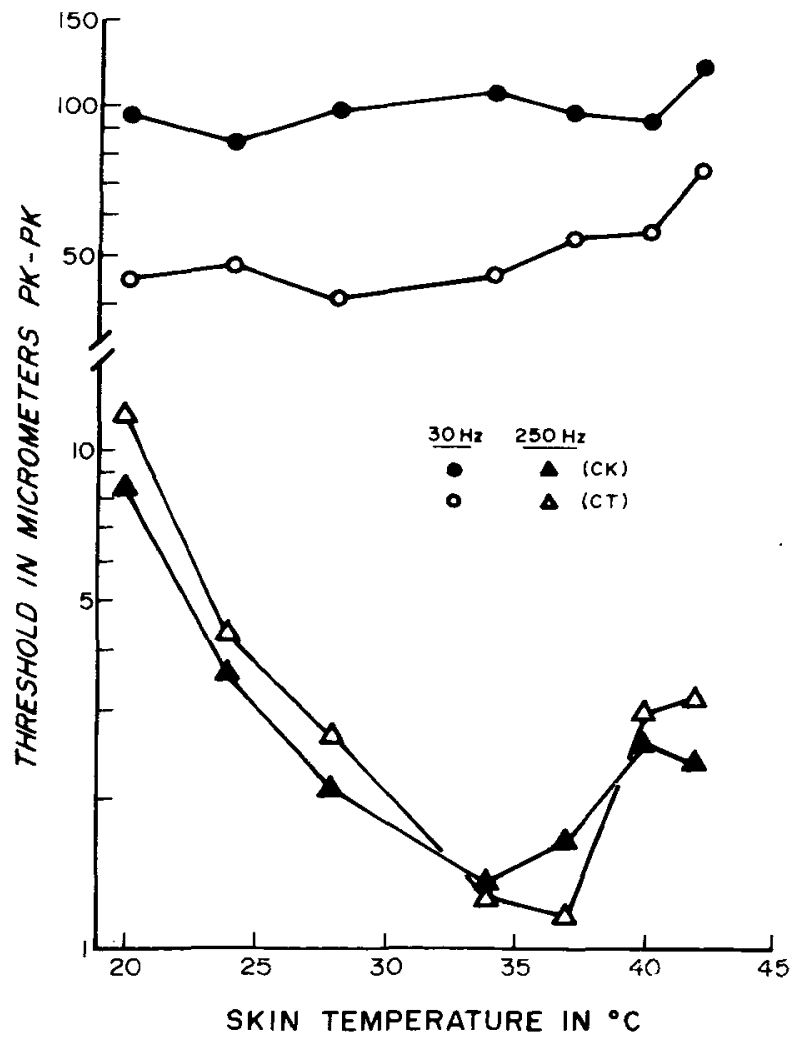

Figure 2. Median threshold values for 30- and 250-Hz vibration as a function of skin temperature in micrometers peak-topeak. Data are for two subjects (filled symbols, C.K., empty symbols, C.T.).

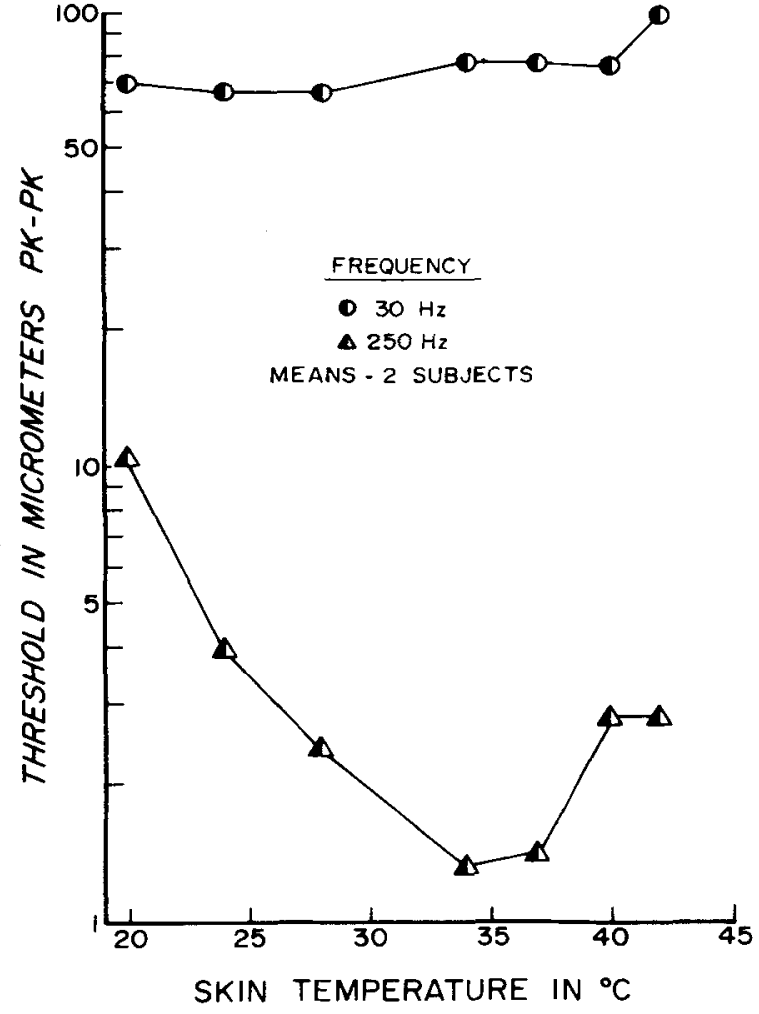

Figure 3. The data of Figure 2 averaged across subjects (0-30 Hz, $\triangle-250 \mathrm{~Hz})$.

dramatic: Cooling to $20^{\circ} \mathrm{C}$ causes a 17.5 -dB decrement in sensitivity at $250 \mathrm{~Hz}$, but causes only a 1-dB decrement at $30 \mathrm{~Hz}$. Warming to $42^{\circ}$ causes a $6.5-\mathrm{dB}$ decrement in sensitivity at $250 \mathrm{~Hz}$, and a $2.3-\mathrm{dB}$ decrement at $30 \mathrm{~Hz}$.

The contrasting results for $30-$ and $250-\mathrm{Hz}$ stimuli is compelling evidence that the effect of temperature on the detection of mechanical stimuli is not uniform. In view of the psychophysical and electrophysiological data supporting the notion that vibration is mediated by at least two types of receptors, the most straightforward explanation of these results is that temperature (particularly cooling) alters the sensitivity of Pacinian corpuscles but leaves other vibration-sensitive receptors unaffected.

If receptor type is responsible for the presence or absence of the thermal effect, then the magnitude of the effect should vary in a systematic way across frequencies. Thresholds should be influenced by temperature only at vibration frequencies mediated primarily by Pacinian corpuscles-generally frequencies above $40-80 \mathrm{~Hz}$. Experiment 2 tests this hypothesis by measuring vibrotactile thresholds between 30 and $250 \mathrm{~Hz}$ at three skin temperatures.

\section{EXPERIMENT 2}

\section{Method}

Subjects. The subjects were the same three as in Experiment 1 . 


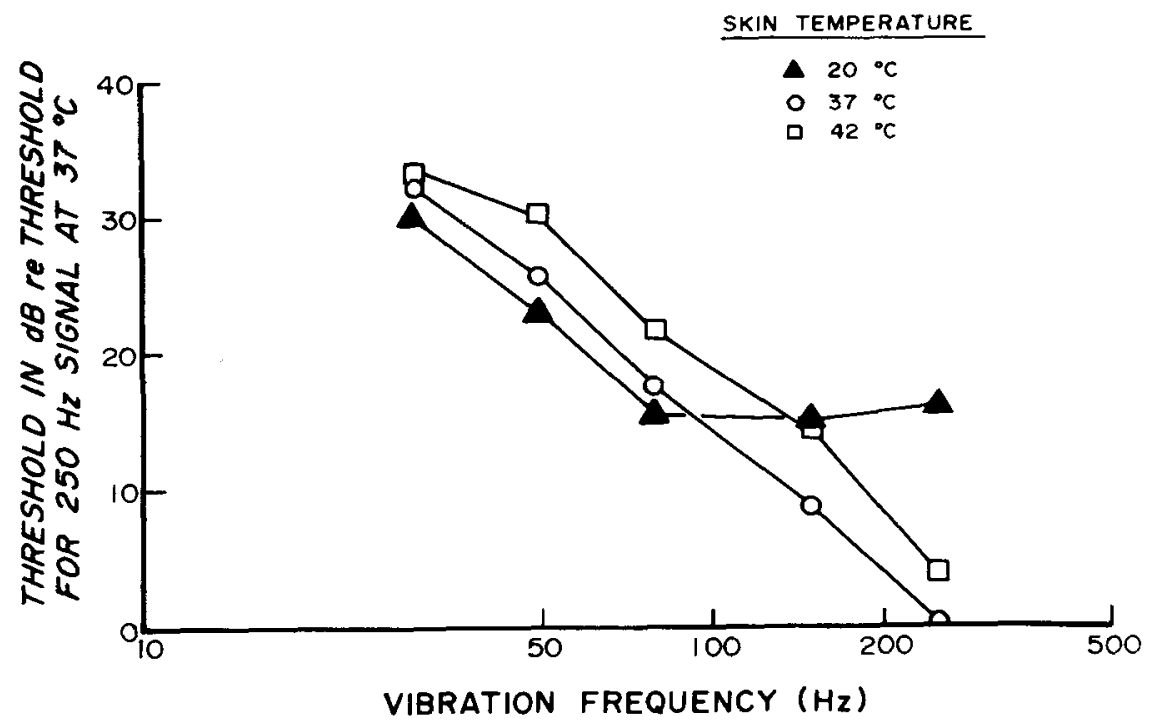

Figure 4. Threshold as a function of frequency at three temperatures. Decibel values were calculated by first determining thresholds in decibels re threshold for the $250-\mathrm{Hz}$ stimulus at $37^{\circ} \mathrm{C}$ for each subject, and then taking the median decibel values across subjects. Reference amplitudes were: $0.4 \mu$ for D.S., $2.0 \mu$ for C.K., and $1.9 \mu$ for C.T.

Procedure. The apparatus and procedure were the same as those of Experiment 1, except that three skin temperatures $\left(20^{\circ}, 37^{\circ}\right.$, and $\left.42^{\circ} \mathrm{C}\right)$ and five frequencies $(30,50,80,150$, and $250 \mathrm{~Hz}$ ) were tested. These changes required that five thresholds (one at each frequency) be run during each water immersion. This typically took $7-8 \mathrm{~min}$. There were no noticeable changes in the skin during an immersion. Frequencies and temperatures were tested randomly to avoid possible order effects.

Five observations per subject were recorded for each of the 15 combinations of frequency and temperature (5 frequencies $x$ 3 temperatures).

\section{Results}

Pooled data for three subjects (medians of medians) expressed as differences in decibels are plotted in Figure 4. (Decibel differences were used to obviate problems posed by the varied sensitivities among subjects.) Skin temperature is the parameter.

The findings of Experiment 1 were replicated. In addition, cooling to $20^{\circ} \mathrm{C}$ blunted sensitivity to 150 $\mathrm{Hz}$ vibration, whereas cooling slightly enhanced sensitivity to $30-, 50-$, and $80-\mathrm{Hz}$ stimuli. The effect of cooling at 150 and $250 \mathrm{~Hz}$ was greater than the effect of warming, but warming tended to reduce sensitivity to some degree at each frequency.

Figure 5 offers a summary of the data of Experiment 2, graphed with the results of Experiment 1 in mind. Idealized curves drawn through the data at each frequency suggest how the underlying functions may vary across frequencies. The more complete functions for 30 - and $250-\mathrm{Hz}$ vibration from Experiment 1 (Figure 3) served as models for the low- and high-frequency curves. Notice that the shape of the $250-\mathrm{Hz}$ function is uncertain at high temperatures, since in Experiment 1 thresholds at $40^{\circ}$ and $42^{\circ} \mathrm{C}$ were nearly identical.

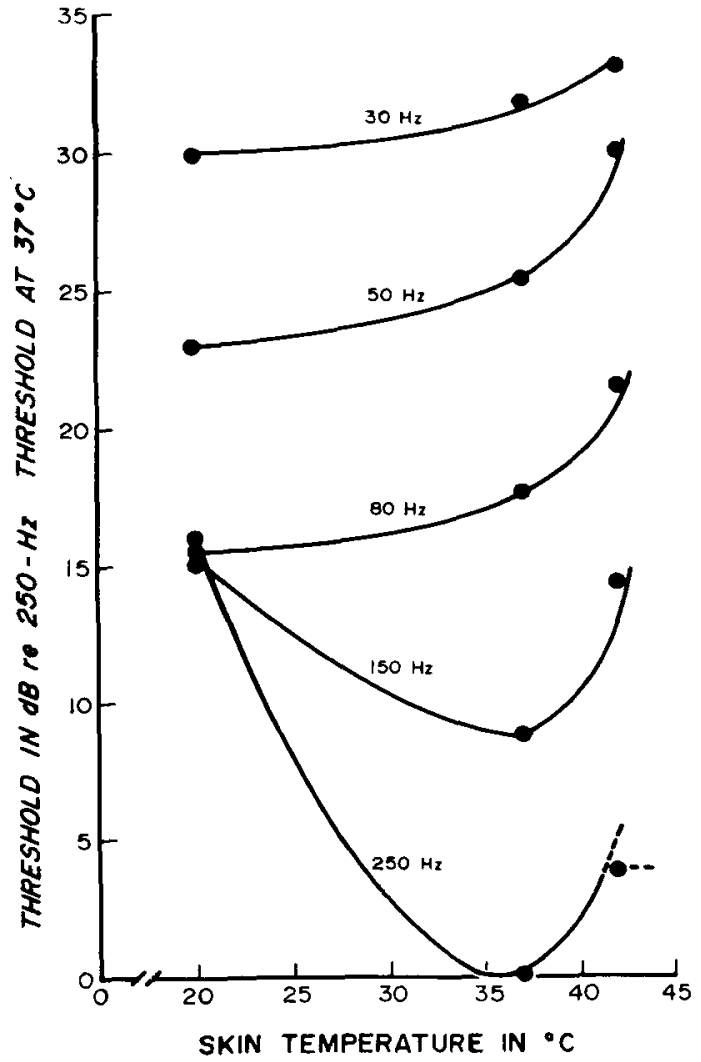

Figure 5. Threshold as a function of skin temperature for five frequencies. The curves are idealized and based upon the more complete 30- and $250-\mathrm{Hz}$ functions of Figure 3 . Sensitivity is shown as decreasing between $37^{\circ}$ and $42^{\circ} \mathrm{C}$ at all frequencies, whereas threshold suffers from cooling to $20^{\circ} \mathrm{C}$ only at 150 and $250 \mathrm{~Hz}$. 


\section{DISCUSSION}

The two experiments reported here demonstrate that skin temperature is crucial to vibrotactile sensitivity only when variation frequency is high $(>80 \mathrm{~Hz})$. The data reported by Weitz (1941) had heretofore given the impression that vibrotactile sensitivity in general was dramatically influenced by skin temperature. This position must now be reevaluated.

The duplex mechanoreceptor hypothesis (Verrillo, 1968) seems to offer a parsimonious explanation for the present results: Temperature affects transduction in one type of receptor (the Pacinian corpuscle) but not in another.

Electrophysiological data exist which support one side of this interpretation. Inman and Peruzzi (1961) measured the effect of temperature on the mechanical generation of both the receptor potential and nerve impulse in Pacinian corpuscles. The mechanical stimuli were square-wave pulses of $7 \mathrm{msec}$ duration delivered to the surface of the corpuscle. Of greatest importance to the present study was their finding that the temperature coefficient $\left(Q_{10}\right)$ for mechanical generation of action potentials was -2.3 between $37^{\circ}$ and $17^{\circ} \mathrm{C}$. This $\mathrm{Q}_{10}$ corresponds to an amplitude change of $15 \mathrm{~dB}-$ a value close to the threshold change observed in the present study for the $250-\mathrm{Hz}$ stimulus between $20^{\circ}$ and $37^{\circ} \mathrm{C} .{ }^{2} \mathrm{~A}$ study by Ishiko and Loewenstein (1961) also investigated the effect of temperature on Pacinian corpuscles, and, though their results were not in complete accord with those of Inman and Peruzzi, they too found that transduction was influenced by temperature. From Ishiko and Loewenstein's Figure 9 (p. 115), it can be seen that the mechanical threshold for production of a nerve impulse increased approximately $11 \mathrm{~dB}$ as temperature dropped from $37^{\circ}$ to $20^{\circ} \mathrm{C}$. Ishiko and Loewenstein reasoned that the increase in mechanical threshold was due to an observed decrease in both the amplitude and rise time of the receptor potential as temperature decreased. Additionally, the absolute refractory period increases with a drop in temperature, which may also affect vibrotactile thresholds (Ishiko \& Loewenstein, 1961). Testing at $24^{\circ}$ and $37^{\circ} \mathrm{C}$, Sato (1961) demonstrated in a single Pacinian corpuscle that cooling shifts the minimum in the U-shaped function to a lower frequency. Sensitivity at $24^{\circ} \mathrm{C}$ became worse for frequencies above $200 \mathrm{~Hz}$, and better for frequencies below $200 \mathrm{~Hz}$. Figure 4 shows basically the same trend, since at $20^{\circ} \mathrm{C}$ thresholds are higher at 150 and $250 \mathrm{~Hz}$, whereas thresholds are slightly lower at $80 \mathrm{~Hz}$ and below. The point of maximum sensitivity seems to have shifted from $250 \mathrm{~Hz}$ to between 80 and $150 \mathrm{~Hz}$.

The Pacinian corpuscle explanation, however, fails to account for all of the data. What of the effect of warming the skin? The absence of a clear depend- ence upon frequency suggests that the effect of warming involves a different process from the one responsible for the effect of cooling. Electrophysiological data on influences of warming are sparse. Inman and Peruzzi tested only temperatures $37^{\circ} \mathrm{C}$ and below; Ishiko and Loewenstein measured mechanical thresholds at temperatures up to $40^{\circ} \mathrm{C}$, but found no increase in threshold for mechanical stimulation. It is possible that temperatures above $37^{\circ} \mathrm{C}$ change the tissue and/or blood supply surrounding the receptors, which may in turn diminish vibrotactile sensitivity. Weitz (1941), however, tested for effects of vasodilation and found none.

The findings of Weitz, which on first inspection are handled easily by the Pacinian corpuscle interpretation, may also require additional assumptions. There is some doubt that Weitz was stimulating Pacinian corpuscles when he used a $.0006-\mathrm{cm}^{2}$ contactor to stimulate "spots" on the hairy skin of the arm. The exacting work of Geldard (1976) provides convincing evidence that vibration-sensitive "spots" on hairy skin are related to "basket" nerve endings at the base of hairs. This implies that the sensitivity of basket endings must be altered by temperature in a way similar to that observed in Pacinian corpuscles. Thus we are forced to consider a more general "receptor-locus" explanation of the effect of temperature.

A similar problem occurs when considering the effect of temperature on punctiform touch (Allers \& Halpern, 1922; Moore, 1910). Pacinian corpuscles are quickly adapting and require a high-velocity stimulus to be excited (Sato, 1961). Consequently, they are poor candidates to be the receptors for pressure stimuli (Harrington \& Merzenich, 1970). Alternatively, if "pressure" receptors are responsible for the effect, they must be influenced by temperature in the same way as are Pacinian corpuscles. But whether or not receptors sensitive to pressure should be included in a broad receptor-locus explanation of temperature effects is at present problematic. Recent experiments in this laboratory failed to find an effect of cooling on thresholds for punctate pressure until skin temperature dipped below $20^{\circ} \mathrm{C}$ (Stevens, Green, \& Krimsley, in press). Comparably low temperatures are required before spatial discrimination on the skin is disturbed (Mills, 1956; Provins \& Morton, 1960). Thus the results for pressure are ambiguous and await further research for clarification.

To summarize, the present results indicate that when measured on glabrous (hairless) skin, cooling impairs sensitivity to high-frequency vibration. This may be related to the high $Q_{10}$ of Pacinian corpuscles. Warming the skin lowers sensitivity somewhat over a wide range of frequencies. This effect seems to be independent of receptor type. In general, the data for vibration on both hairy and glabrous skin 
indicate that skin temperature is often, but not always, a factor in detection of vibrotactile stimuli. An obvious related question is: Does temperature also influence the perceived magnitude of vibrotactile stimuli?

\section{REFERENCES}

Allers, R., \& Halpern, F. Wechselwirkungen gleichzeitiger Erregung mehrerer Hautsinne. 1. Mitteilung. Die Bleinflussung der Tastschwelle durch die Hauttemperatur. Pflügers Archiv für die Gesamte Physiologie, 1922, 193, 595-609.

BÉKÉsy, G. von. Experiments in hearing. New York: McGrawHill, 1960.

GELDARD. F. A. Vibratory reception in hairy skin. In G. B. Flores d'Arcais (Ed.), Festschrift for Fabio Metelli. Milan: Martello-Giunti, 1976. Pp. 301-311.

Harrington, T., \& Merzenich, M. M. Neural coding in the sense of touch. Experimental Brain Research, 1970, 10, 251-254.

Inman, D. P., \& Peruzzi, P. The effects of temperature on the responses of Pacinian corpuscles. Journal of Physiology, 1961. 155. 280-301.

Ishiko, N., \& Loewenstein, W. R. Effects of temperature on the generator and action potentials of a sense organ. Journal of General Physiology, 1961, 45, 105-124.

Merzenich, M. M., \& Harrington, T. The sense of fluttervibration evoked by stimulation of the hairy skin of primates. Comparison of human capacity with the responses of mechanoreceptive afferents innervating the hairy skin of monkeys. Experimental Brain Research, 1969, 9, 236-260.

Mills. A. W. Finger numbness and skin temperature. Journal of Applied Physiology. 1956, 9, 447-450.

MoORE, T. V. The influence of temperature and the electric current on the sensibility of the skin. Psychological Review, 1910. 17. 347-386.

Mountcastle, V. B., Talbot, W. H., Darian-Smith, I., \& Kornhuber. H. H. Neural basis of the sense of fluttervibration. Science, 1967. 155, 597-600.

Provins. K. A., \& Morton. R. Tactile discrimination and skin temperature. Journal of Applied Physiology, 1960, 15, 155-160.

Sato, M. Response of Pacinian corpuscles to sinusoidal vibration. Journal of Physiology, 1961, 159, 391-409.

Stevens, J. C., Green, B. G., \& Krimsley, A. S. Punctate pressure sensitivity: Effects of skin temperature. Sensory Processes, in press.

Talbot, W. H., Darian-Smith, I., Kornhuber, H. H., \& MountCastle, V. B. The sense of flutter-vibration: Comparison of the human capacity with response patterns of mechanoreceptive afferents from the monkey hand. Journal of Neurophysiology, 1968, 31, 301-334.

VERRILLO, R. T. Investigation of some parameters of the cutaneous threshold for vibration. Journal of the Acoustical Society of America, 1962. 34. 1768-1773.

VERRILlo. R. T. Effect of contactor area on vibrotactile threshold. Journal of the Acoustical Society of America, 1963. 35. 1962-1966.

VERRILLO, R. T. A duplex mechanism of mechanoreception. In D. R. Kenshalo (Ed.), The skin senses. Springfield, Ill: Thomas, 1968.

WeITz, J. Vibratory sensitivity as a function of skin temperature. Journal of Experimental Psychology, 1941, 28, 21-36.

\section{NOTES}

1. Verrillo typically reports a threshold function with a slope of zero at low frequencies, and a slope of $-12 \mathrm{~dB}$ per doubling of frequency at high frequencies. The psychophysical evidence for two vibration-sensitive afferent systems comes in part from this difference in slope (Verrillo, 1963). The threshold function of Figure 1, which has a uniform slope across frequencies, might be interpreted to mean that the receptor duplexity is absent here. Such an interpretation is probably incorrect. Early work by Verrillo (1962) shows that a two-limb threshold function is obtained only when a rigid surround (with a $1-\mathrm{mm}$ gap) is used. The prototypic threshold function, obtained without a surround, mirrors the present results (see Verrillo, 1962, Figure 6, p. 1771, for example). While no satisfactory explanation exists for the effect of the surround on the frequency-intensity function, it is likely that the surround modifies the patterns of responding of populations of the adjacent mechanoreceptors.

2. The formula used by Inman and Peruzzi (1961) for $Q_{10}$ was the following one:

$$
\mathrm{Q}_{10}=\frac{\frac{\mathrm{X}_{\mathrm{T}_{0}}+10\left(\mathrm{X}_{\mathrm{T}}-\mathrm{X}_{\mathrm{T}_{0}}\right)}{\left(\mathrm{T}-\mathrm{T}_{0}\right)}}{\mathrm{X}_{\mathrm{T}_{0}}},
$$

where $T_{0}$ is the lower temperature, $T$ is the higher temperature, $\mathrm{X}_{T_{0}}$ is the mechanical threshold for initiation of an action potential at $T_{0}$, and $X_{T}$ is the mechanical threshold at $T$. The $Q_{10}$ of -2.3 was converted into an amplitude difference in decibels by plugging-in arbitrary values of $\mathrm{X}_{\mathrm{T}_{0}}$ and solving for $\mathrm{X}_{\mathrm{T}}$. The ratio of $\mathrm{X}_{\mathrm{T}}$ to $\mathrm{X}_{\mathrm{T}_{0}}$ was then converted to a difference in decibels using the formula

$$
\Delta \mathrm{dB}=20\left[\log \mathrm{X}_{\mathrm{T}} / \mathrm{X}_{\mathrm{T}_{0}}\right]
$$

(Received for publication October 20, 1976; revision received December $20,1976$. ) 